\title{
Optimization of electrochemical doping approach resulting in highly photoactive iodine-doped titania nanotubes
}

\author{
M. Szkoda ${ }^{1} \cdot$ K. Siuzdak ${ }^{2} \cdot$ A. Lisowska-Oleksiak ${ }^{1}$
}

Received: 13 August 2015 / Revised: 8 November 2015 / Accepted: 9 November 2015 / Published online: 17 November 2015

(C) The Author(s) 2015. This article is published with open access at Springerlink.com

\begin{abstract}
The paper focuses on the optimization procedure concerning the synthesis method resulting in highly ordered titania nanotubes doped with iodine atoms. The doping process was based on the electrochemical treatment of a titania nanotube layer immersed in a potassium iodide (KI) solution acting as an iodine precursor. A number of endeavors were undertaken in order to optimize the doping conditions. Electrolyte concentration, reaction voltage, and time/duration were the main factors that influenced the iodine (I)-doping effect on the photoactivity. The parameters of electrochemical doping that result in a material characterized by the highest photocurrent density are as follows: reaction voltage of $1.5 \mathrm{~V}$, duration of $15 \mathrm{~min}$, and $0.1 \mathrm{M} \mathrm{KI}$. Different spectroscopic techniques, i.e., UV-Vis spectroscopy, Raman spectroscopy, and X-ray photoelectron spectroscopy were used to characterize the absorbance capability and the crystalline phase, to confirm the presence of iodine atoms and to study the nature of chemical compounds. The morphology inspection performed by means of scanning electron microscopy shows that the doping process does not affect the ordered tubular architecture. The photocurrent densities of the I-doped sample were six times higher in comparison to those generated by the pure titania nanotube electrode. Moreover, doped samples act as a much better catalyst in the photodegradation process of
\end{abstract}

M. Szkoda

mariusz-szkoda@wp.pl

1 Department of Chemistry and Technology of Functional Materials, Chemical Faculty, Gdańsk University of Technology, Narutowicza 11/12, Gdańsk 80-233, Poland

2 Centre for Plasma and Laser Engineering, Szewalski Institute of Fluid Flow Machinery, Polish Academy of Sciences, Fiszera 14, Gdańsk 80-231, Poland methylene blue and formation of hydroxyl radicals $(\bullet \mathrm{OH})$ than undoped samples.

Keywords Anodization $\cdot$ Iodine-doped $\cdot \mathrm{TiO}_{2}$ nanotubes . Photoactivity $\cdot$ Electrochemical doping

\section{Introduction}

$\mathrm{TiO}_{2}$ is currently one of the most studied compounds in materials science. Owing to some outstanding properties (high photo and chemical stability, photocatalytic activity, low cost, and nontoxicity), it is frequently used in photocatalytic removal of organic contaminations [1], hydrogen generation based on the water splitting process [2, 3], solar cells [4], and biomedical devices [5]. In 1999, Zwilling et al. [6] first reported the electrochemical formation of the self-assembled, highly ordered arrays of $\mathrm{TiO}_{2}$ nanotubes via the anodization process of a titanium metal plate. These findings intensified the research activities that focused on growth, modification, properties, and other possible application areas of these onedimensional (1D) nanostructures. However, the activity of titania nanotubes in processes carried out under illumination is limited by their wide bandgap $E_{\mathrm{bg}}$ that corresponds to energy provided by ultraviolet light [7]. Therefore, different strategies were proposed in order to shift the activity of titania towards longer wavelengths. Among them, doping with non-metal atoms is regarded as simple and effective, providing materials that are stable and that exhibit their activity under visible light illumination. For the intentional doping of titania, nitrogen [8], sulfur [9], phosphorus [10], boron [11, 12], and iodine [13] atoms were proposed as favorable non-metallic candidates. Taking into account a number of scientific reports, nitrogen and boron are the most popular dopant atoms, and their presence in titania structures results in a highly active material, 
Table 1 Factors and levels for experiments to optimize the doping

\begin{tabular}{llll}
\hline Factors & \multicolumn{2}{l}{ Levels } \\
\cline { 2 - 4 } & 1 & 2 & 3 \\
\hline Electrolyte concentration [M] & 0.1 & 0.5 & 1 \\
Reaction voltage [V] & 0.5 & 1.5 & 3 \\
Reaction time [min] & 5 & 15 & 45 \\
\hline
\end{tabular}

whereas the investigation of other possible non-metal atoms is not as widespread. In the case of iodine-doped $\mathrm{TiO}_{2}$ nanotubes, many of the fundamental properties and characteristics of this material have been investigated [13]; however, transient photocurrent stability and generation efficiency of hydroxyl radicals were not studied in details. Here, we focus on a successful optimization strategy for iodine doping of titanium dioxide via an electrochemical process performed on freshly formed titania nanotubes immersed in a potassium iodide (KI) solution.

Despite the vast number of reports on titania nanotubes, no influence of doping parameters on the photoactivity was shown. Thus, we have performed an experiment to optimize the doping conditions in order to obtain the best photocatalytic activity. Materials were characterized using various spectroscopic techniques: UV-Vis, Raman, XRD, and X-ray photoelectron spectroscopy. The morphology and the elemental analysis were studied using the SEM equipped with EDX. The photoactivity of doped and pure nanotube array films was tested during a photocatalytic process, photocurrent measurements and as a formation efficiency of hydroxyl radicals $(\bullet \mathrm{OH})$ on the surface of illuminated samples.

\section{Experimental}

\section{Material preparation}

Titania nanotubes were prepared via anodization of a titanium metal plate (Steam, $99.7 \%$ ) performed in a fluoride-rich solution. The procedure that leads to the formation of $\mathrm{TiO}_{2}$ nanotubes was described in our previous report [8]. To sum it up briefly, the procedure is based on a two-stage anodization process providing highly ordered nanotubular architecture
[14]. The first and the second steps were performed in the same conditions: temperature $\left(23^{\circ} \mathrm{C} \pm 1{ }^{\circ} \mathrm{C}\right)$, electrolyte composition $\left(0.27 \mathrm{M} \mathrm{NH}_{4} \mathrm{~F}\right.$ in $1 \% / 99 \% \mathrm{v} / \mathrm{v}$ water/ethylene glycol solution), and anodization parameters (40 V, $2 \mathrm{~h})$. Before the second anodization process, the as-formed nanotubes during the first step were removed by overnight etching in an oxalic acid solution $(0.5 \% \mathrm{wt})$. Finally, the titanium plates covered with nanotubes were ultrasonically cleaned in diluted HF in order to remove surface debris.

Iodine doping was performed during an additional electrochemical process, in a two electrode assembly, where the previously prepared titania nanotubes served as an anode and the Pt mesh plate as a cathode. The electrolyte was a solution of potassium iodide (KI). The optimization of the electrochemical doping approach was realized in different conditions. According to the information listed in Table 1, the doping experiments were carried out with three factors and three levels, namely KI concentration $(0.1,0.5$, and $1 \mathrm{M})$, reaction voltage $(0.5,1.5$, and $3 \mathrm{~V})$, and reaction time $(5,15$, and $45 \mathrm{~min})$, respectively.

The prepared samples, pure and iodine-doped titania nanotubes, were rinsed in deionized water and annealed at temperature of $450{ }^{\circ} \mathrm{C}$ for $2 \mathrm{~h}$ (heating rate $2{ }^{\circ} \mathrm{C} \min ^{-1}$ ) in order to transform the amorphous titania into the crystalline phase.

\section{Characterization}

The morphology and cross-section of the samples were investigated by means of the Schottky field emission scanning electron microscopy (FEI Quanta FEG 250) with ET secondary electron detector. For an elemental analysis, the energydispersive X-ray spectroscopy was performed by means of the EDAX Genesis APEX $2 \mathrm{i}$ with the ApolloX SDD spectrometer in a particular area of each sample. The UV-Vis reflectance spectra of titania nanotubes were measured with a dual beam UV-Vis spectrophotometer (Lambda 35, Perkin Elmer) equipped with a diffuse reflectance accessory. Bandgap energy values were determined as the intercept of the tangent of the plot of transformation of the Kubelka-Munk function $\left(\mathrm{KM}^{0.5} E_{\mathrm{ph}}{ }^{0.5}\right)$ vs. photon energy, where $\mathrm{KM}=(1-\mathrm{R})^{2} / 2 \mathrm{R}$, $\mathrm{R}$ - the intensity of radiation reflected from the sample. The exponent applied at the Kubelka-Munk function is related with the type of bandgap transition. Because titanium dioxide is characterized by a direct bandgap, the value of exponent
Fig. 1 Surface SEM image of titania nanotube arrays: pure (a), $\mathrm{I}-\mathrm{TiO}_{2}$ (b), high-resolution image of $\mathrm{I}_{-} \mathrm{TiO}_{2}$ (c). The doping conditions are as follows: reaction voltage is $1.5 \mathrm{~V}$, reaction time is $15 \mathrm{~min}$, and electrolyte concentration is $0.1 \mathrm{M}$

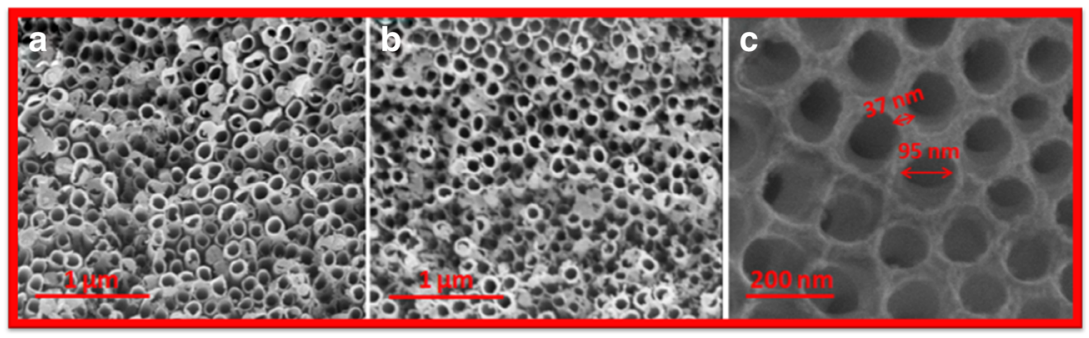



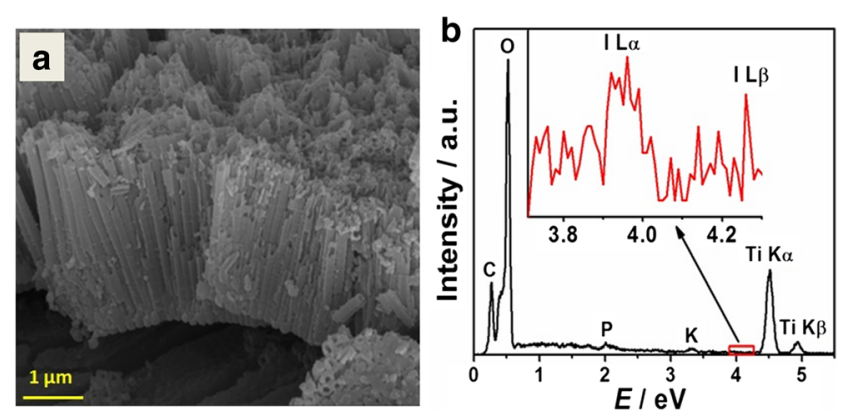

Fig. 2 a Cross-section image of the titania nanotube layer of $\mathrm{I}_{-}-\mathrm{TiO}_{2}$ and b EDX analysis at the top and at the bottom level of the titania layer. The doping conditions are as follows: reaction voltage is $1.5 \mathrm{~V}$, reaction time is $15 \mathrm{~min}$, and electrolyte concentration is $0.1 \mathrm{M}$

equals 0.5 [15]. The Raman spectra were recorded by a confocal micro-Raman spectrometer (InVia, Renishaw) with sample excitation, by means of an argon ion laser emitting at 514 . The crystalline phase of obtained materials was identified by X-ray diffraction (XRD, Rigaku Miniflex 600) analysis. The measurement was performed with $\mathrm{Cu} \mathrm{K} \alpha$ radiation at $2 \theta$ angles from $5^{\circ}$ to $90^{\circ}$ with scan speed of $0.02^{\circ} \mathrm{min}^{-1}$. Crystallite size was calculated from the half height width of the (101) diffraction peak of anatase using the Scherrer equation. Escalab 250Xi by ThermoFisher Scientific was used to carry out high-resolution X-ray photoelectron spectroscopy (XPS) measurements to determine the chemical binding properties of the surface, utilizing monochromatic $\mathrm{Al} \mathrm{K} \alpha$ source with charge neutralization implemented by means of a flood gun. High-resolution spectra were recorded at energy step size of $0.1 \mathrm{eV}$ at pass energy of $10 \mathrm{eV}$. In order to normalize spectroscopic measurements, $X$ axis (binding energy, $E_{\text {bin }}$ ) from XPS spectrum was calibrated for peak characteristics of neutral carbon $1 \mathrm{~s}\left(E_{\mathrm{bin}}=284.6 \mathrm{eV}\right)$. Data analysis was performed using the Avantage software provided by the manufacturer.

\section{Photocurrent measurement}

The photoelectrochemical studies on pure and iodine-doped titania nanotubes were conducted using the AutoLab PGStat $302 \mathrm{~N}$ potentiostat-galvanostat system (Methrom, AutoLab) in the standard three-electrode arrangement, where titanium foil covered by nanotubes served as a working electrode (active surface area of $0.5 \mathrm{~cm}^{2}$ ). The Pt mesh was used as a counter electrode, while $\mathrm{Ag} / \mathrm{AgCl} / 0.1 \mathrm{M} \mathrm{KCl}$ as a reference electrode. All electrochemical tests were carried out in deaerated $0.5 \mathrm{M}$ $\mathrm{K}_{2} \mathrm{SO}_{4}$. The photocurrent was registered at the working electrode potential of $+0.5 \mathrm{~V}$ vs. $\mathrm{Ag} / \mathrm{AgCl} / 0.1 \mathrm{M} \mathrm{KCl}$. A $150 \mathrm{~W}$ xenon lamp (Osram XBO 150; AM1.5 filter) was used as a light source with irradiation intensity adjusted to $100 \mathrm{~mW} \mathrm{~cm}{ }^{-2}$ (Ophir) of methylene blue solution (MB) with the same illumination conditions as during the photoelectrochemical measurements. A titanium plate (surface of 1 and $4 \mathrm{~cm}^{2}$ ) covered by pure and doped nanotube arrays was immersed in $10 \mu \mathrm{mol} / \mathrm{dm}^{3}$ methylene blue solution and exposed to irradiation after $30 \mathrm{~min}$ (needed to reach equilibrium of adsorption). The concentration of MB during decomposition was monitored every 10 min using the Lambda 35 UV-Vis spectrophotometer (Perkin Elmer). The blank experiment was carried out under the same conditions but without any catalyst samples immersed in the solution. Additionally, the generation of hydroxyl radical $(\cdot \mathrm{OH})$ illuminated under a xenon lamp (Osram XBO 150 with AM1.5 filter) for pure and doped $\mathrm{TiO}_{2}$ nanotubes was detected by means of the photoluminescence technique using the terephthalic acid (TA) as a probe molecule. The geometric area of the sample immersed in TA solution was $2.5 \mathrm{~cm}^{2}$. Under illumination, terephthalic acid easily reacts with $\cdot \mathrm{OH}$ to produce a highly fluorescent product, 2 hydroxyterephthalic acid [16]. The intensity of the PL peak of 2-hydroxyterephthalic acid is directly proportional to the amount of formed $\bullet \mathrm{OH}$ radicals [17]. The initial concentration of TA was $50 \mathrm{mM}$ in $2 \mathrm{mM} \mathrm{NaOH}$.

\section{Results and discussion}

\section{Morphology and structure studies}

Figure 1 presents the top-view morphologies of pure and doped titania nanotubes. Since the morphologies for the entire set of prepared iodine (I)-doped TNT arrays samples were similar, we have shown here a representative sample after a
Fig. 3 a Absorbance spectra and the Kubelka-Munk function for pure and doped titania and $\mathbf{b}$ Raman spectra for pure and iodine-doped titania. The doping conditions are as follows: reaction voltage of $1.5 \mathrm{~V}$, reaction time of $15 \mathrm{~min}$, and electrolyte concentration of $0.1 \mathrm{M}$
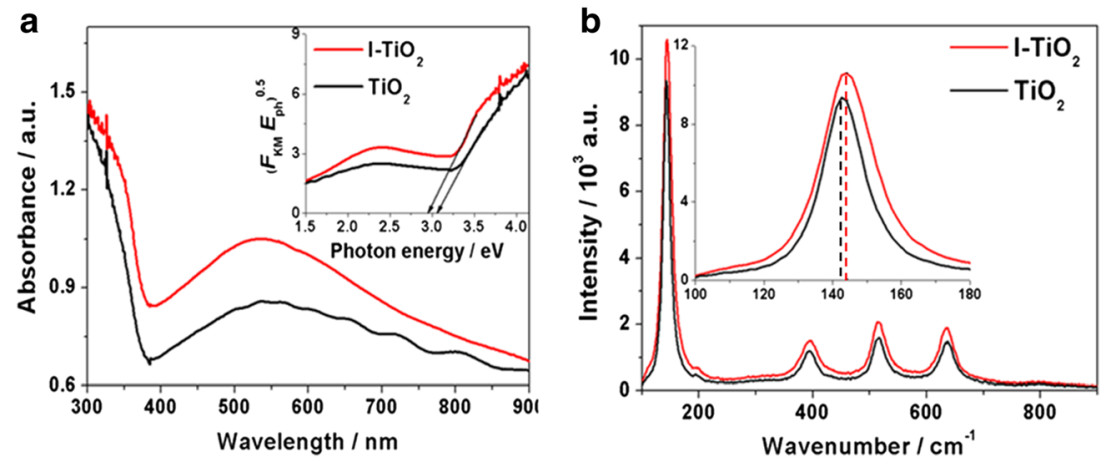
doping procedure performed under $1.5 \mathrm{~V}$, for $15 \mathrm{~min}$ and in 0.1-M-concentrated KI solution. The uniform layers obtained are composed of highly ordered and aligned tubes. When comparing SEM images, no difference was observed in the nano-architecture between the doped and undoped materials. Thus, electrochemical doping does not affect the morphology, and only the presence of dopant atoms can have an impact on their structural properties and photoactivity. Images registered at much higher magnification (see Fig. 1c) allow definition of the tube dimensions: $95 \mathrm{~nm}$ in diameter and $37 \mathrm{~nm}$ of wall thickness at the top level of the entire titania layer. As it can be seen in Fig. 2, the SEM image at the cross-section of iodinedoped $\mathrm{TiO}_{2}$ was also taken together with the EDX analysis. The tube length for $\mathrm{I}^{-\mathrm{TiO}_{2}}$ was $2.2 \mu \mathrm{m}$ - the same length as for the undoped material. Apart from the titanium, carbon, potassium, and oxygen, the signal attributed to iodine was also detected at the level of 0.31 at $\%$. This allows us to conclude that the electrochemical doping strategy leads to the introduction of iodine atoms into the titania nanotube layer.

In Fig. 3a, the absorbance curves and the Tauc plot are shown. As it is typical for titanium dioxide materials, the highest absorbance was registered in the UV range [18]. An additional wide absorption band is present in the visible range with maximum at $550 \mathrm{~nm}$, which could be assigned to the presence of some sub-bandgap states resulting from the unique structure of the titania nanotube [8]. In the case of doped samples, the absorbance in the range of $450-900 \mathrm{~nm}$ is more intensive when compared to a pure sample. Based on the Tauc plot, the bandgap energy value was determined and equals 2.95 for $\mathrm{I}_{-} \mathrm{TiO}_{2}$, whereas for pure $\mathrm{TiO}_{2} E_{\mathrm{bg}}=3.07 \mathrm{eV}$. Such a decrease in $E_{\mathrm{bg}}$ value and enhancement in the absorbance in the visible range is typically observed for titania that was successfully doped with non-metal atoms [19].

In order to verify the crystalline phase of pristine and modified titania, the Raman spectra were recorded and shown in Fig. 3. In general, the Raman spectra for both the undoped and iodine-doped samples are almost the same, indicating that as a result of electrochemical treatment, no significant changes were introduced to the crystal structure of $\mathrm{TiO}_{2}$ nanotubes in iodinecontaining electrolyte. However, a slight shift of $E_{\mathrm{g}(1)}$ maximum from $143.28 \mathrm{~cm}^{-1}$ registered for pure $\mathrm{TiO}_{2}$ towards $144.47 \mathrm{~cm}^{-1}$ for $\mathrm{I}^{-} \mathrm{TiO}_{2}$ can be observed. This shift could result from an increase of crystalline defects formed in the titanium dioxide framework because of the presence of iodine ions [20]. According to Choudhury et al. [21], a change of the $E_{\mathrm{g}(1)}$ band position is caused by the introduction of dopant atoms that disturb the Ti-O-Ti arrangement and generate oxygen vacancies.

Figure 4 shows XRD spectra registered for iodine-doped and pure titania layers. All the crystallite phases could be indexed from their corresponding characteristic peaks using the anatase phase (A) (JCPDS No. 21-1272) and the titanium (Ti) phase (JCPDS No. 44-1294) [22] acting as $\mathrm{TiO}_{2}$ NT support. It should be noted that any peak typical for rutile was not

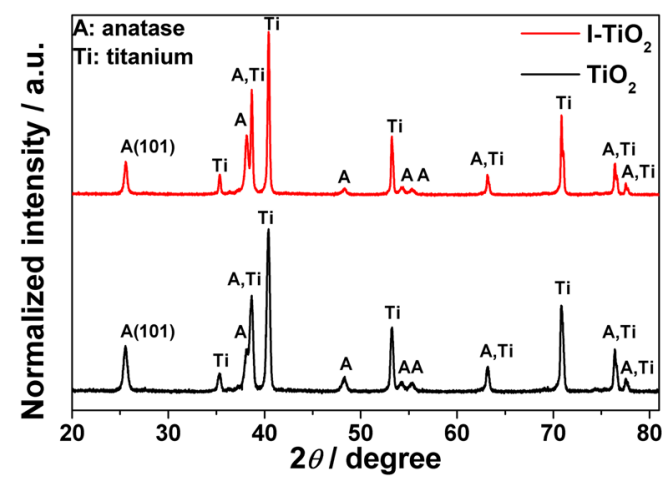

Fig. 4 XRD patterns of pure and I-doped titania. The doping conditions are as follows: reaction voltage of $1.5 \mathrm{~V}$, reaction time of $15 \mathrm{~min}$, and electrolyte concentration of $0.1 \mathrm{M}$

observed. Furthermore, the lack of signal attributed to dopant atoms results from their low content in the material and cannot be detected by XRD [17]. Basing on the Scherrer equation, crystalline size was calculated and equals $17.3 \mathrm{~nm}$ for pure and $25.9 \mathrm{~nm}$ for iodine-doped titania. Increase in crystallite size is probably due to the incorporation of dopant atoms into the structure, e.g., substitution of the lattice oxygen and titanium atoms or introduction of iodine at the interstitial sites [17].

The presence of iodine and its chemical nature in fabricated nanotubes were investigated using the X-ray photoelectron spectroscopy. Figure 5 shows the high-resolution XPS spectra for the iodine reach region that was only found in a doped sample. The XPS spectra as well as the position of each maxima recorded for pure titania nanotubes were described in our previous report [8]. According to these results, relating to undoped and iodine-doped $\mathrm{TiO}_{2}$ nanotubes, the signals typical for $\mathrm{Ti}, \mathrm{O}$, and $\mathrm{C}$ were registered. The positions of maxima of fitted spectra found for doped nanotube arrays as well as for the undoped material are listed in Table 2. The atomic ratio of Ti:O:I is $1: 2.57: 0.080$. The XPS spectra of I $3 d$ region exhibit clear doublet with peaks registered close to 618 and $630 \mathrm{eV}$ similarly to other $\mathrm{I}^{-\mathrm{TiO}_{2}}$ materials $[23,24]$. As it can be seen, these iodine bands were deconvoluted into two doublets, ascribed as: A (617.07 eV; $628.45 \mathrm{eV})$ and $\mathrm{B}(618.40 \mathrm{eV}$;

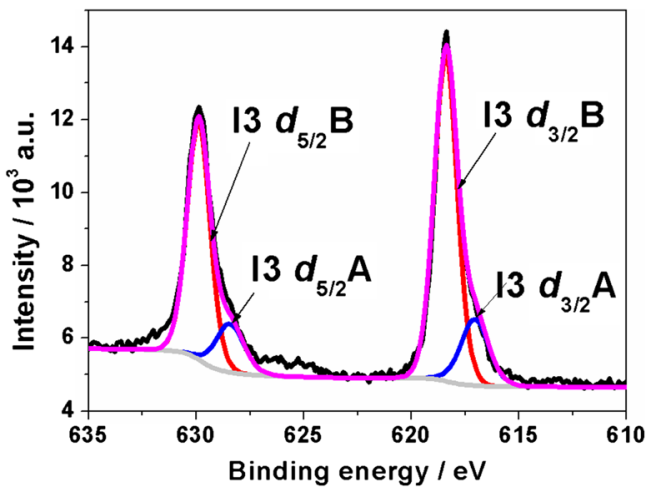

Fig. 5 High-resolution XPS spectra recorded at the iodine region for I$\mathrm{TiO}_{2}$ sample. The doping conditions are as follows: reaction voltage of $1.5 \mathrm{~V}$, reaction time of $15 \mathrm{~min}$, and electrolyte concentration of $0.1 \mathrm{M}$ 
Table 2 The position of species present in a doped and pure $\mathrm{TiO}_{2}$ nanotube. The doping conditions are as follows: reaction voltage of $1.5 \mathrm{~V}$, reaction time of $15 \mathrm{~min}$, and electrolyte concentration of $0.1 \mathrm{M}$

\begin{tabular}{|c|c|c|c|c|c|c|}
\hline \multirow{2}{*}{$\begin{array}{l}\text { Element } \\
\text { Core level }\end{array}$} & \multicolumn{2}{|l|}{ Iodine } & \multicolumn{2}{|l|}{ Titanium } & \multirow{2}{*}{$\begin{array}{l}\text { Oxygen } \\
\text { O1s }\end{array}$} & \multirow{2}{*}{$\begin{array}{l}\text { Carbon } \\
\mathrm{C} 1 s\end{array}$} \\
\hline & $\mathrm{I} 3 d 3 / 2$ & $\mathrm{I} 3 d 5 / 2$ & Ti2 $2 p 1 / 2$ & Ti $2 p 3 / 2$ & & \\
\hline \multirow[t]{3}{*}{$\mathrm{TiO}_{2}$} & - & - & 458.80 & 464.40 & 529.20 & 284.70 \\
\hline & & & & & 531.70 & 286.00 \\
\hline & & & & & & 288.70 \\
\hline \multirow[t]{2}{*}{$\mathrm{I}-\mathrm{TiO}_{2}$} & A: 617.07 & A:628.46 & 458.57 & 464.30 & 529.75 & 284.59 \\
\hline & B:618.40 & B: 629.88 & & & 531.86 & 286.19 \\
\hline
\end{tabular}

$629.88 \mathrm{eV}$ ). To date, such deconvolution into two doublets was reported for iodine-doped graphene oxide [25] or bismuth oxide [26]. Cabibil et al. [27] considered the signals near $620 \mathrm{eV}$ as C-I bonding. On the other hand, the analysis of iodine spectra registered for non-stoichiometric oxide; BOI $_{1.5}$ was fitted with two sets of peaks similarly as in our case. One is attributed to bulk iodine and another to iodine anion from the excess of KI. Thus, because the presence of potassium traces was confirmed on the XPS survey spectra, the most likely interpretation of two doublets in the case of I$\mathrm{TiO}_{2}$ can be attributed to the interstitial iodine and iodine present in KI residues.

A shift in the value of Ti2 $23 / 2$ binding energy for $\mathrm{I}_{-} \mathrm{TiO}_{2}$ can be observed when compared to pure titania, which may be caused by the formation of the new chemical arrangement I-TiO [28]. The bands assigned to oxygen and those found for iodine-doped titania possess their maxima at a higher energy value when compared to the adequate position of $\mathrm{O} 1 s$ for an undoped sample. Such a notable shift of $\mathrm{O} 1 s$ maxima could be due to a partial substitution of oxidation states as reported by Wang et al. [29] in the case of nitrogen- and carbon-doped $\mathrm{TiO}_{2}$.

\section{Photoelectroactivity}

The chronoamperometry measurements performed at working electrode potential $E=+0.5 \mathrm{~V}$ vs. $\mathrm{Ag} / \mathrm{AgCl} / 0.1 \mathrm{M} \mathrm{KCl}$ have enabled the examination of the influence of doping on the photoactivity and photostability of the $\mathrm{TiO}_{2}$ nanotubes. In Fig. 6, the transient photocurrent response is given for the pure and different iodine-doped $\mathrm{TiO}_{2}$ samples registered during the on-off periods of UV-Vis irradiation, whereas Table 3 lists the values of the photocurrent density registered after $8 \mathrm{~min}$ of measurement duration, in addition to the enhancement factors. The enhancement factor was calculated as a ratio between the photocurrent density registered for doped material and pure $\mathrm{TiO}_{2}$. All titania samples doped with iodine, despite different doping conditions, possess much higher photocurrents than pristine titania. Furthermore, the lack of steady current diminution suggests that the material is characterized by resistance to photocorrosion processes. The highest steady-state photocurrent was observed for $\mathrm{I}^{-\mathrm{TiO}_{2}}$ and reached the value of almost $158 \mu \mathrm{A} \mathrm{cm}^{-2}$. Thus, the photocurrents were nearly six times higher than the current registered for pristine titania. According to the values given in Table 3 , the photoelectrochemical properties of I-doped titania nanotubes are strongly dependent on the conditions of the electrochemical doping procedure. It was found that electrolyte concentration, reaction voltage, and reaction time are the three most important parameters that highly influence the effect of iodine doping on material photoactivity. Summarizing, on the basis of the enhancement factor value, the optimal I-doping conditions were determined as follows: reaction voltage is $1.5 \mathrm{~V}$, reaction time is $15 \mathrm{~min}$, and electrolyte concentration is $0.1 \mathrm{M}$.

\section{Photocatalytic properties}

The activity of the prepared samples towards efficient photodegradation of methylene blue (MB) as model organic pollutant was tested in order to compare doped and pure titania as catalytic materials. The progress in photocatalytic degradation of methylene blue under solar light with immersed plates covered by titania nanotubes is presented in Fig. 7a. For comparison, a blank experiment under simulated sunlight irradiation without a photocatalyst sample was also performed. After $2 \mathrm{~h}$ of constant illumination, the degradation of methylene blue reached $40 \%$ for pure $\mathrm{TiO}_{2}$ used as photocatalyst,
Fig. 6 Photocurrent response of pure titania nanotubes (a) and Idoped titania nanotubes (b) arrays samples
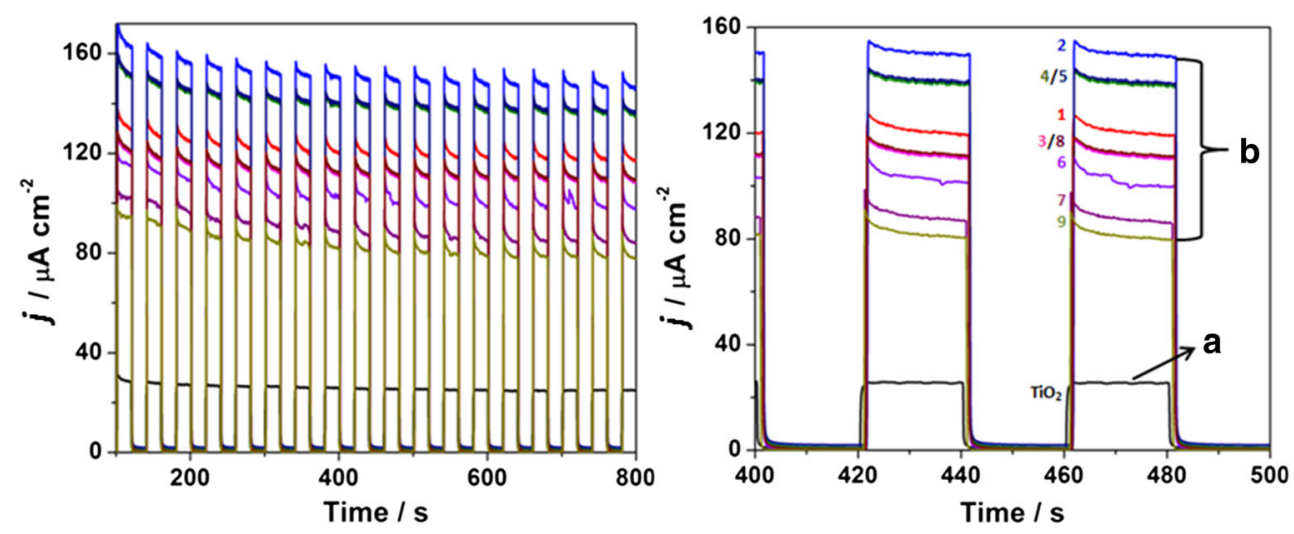
Table 3 Results of the doping experiment

\begin{tabular}{llllll}
\hline $\begin{array}{l}\text { Number } \\
\text { concentration }[\mathrm{M}]\end{array}$ & $\begin{array}{l}\text { Reaction } \\
\text { voltage }[\mathrm{V}]\end{array}$ & $\begin{array}{l}\text { Reaction } \\
\text { time }[\mathrm{min}]\end{array}$ & $\begin{array}{l}\text { The photocurrent } \\
\text { values }\left[\mu \mathrm{A} \mathrm{cm}{ }^{-2}\right]\end{array}$ & $\begin{array}{l}\text { Enhancement } \\
\text { factor }\end{array}$ \\
\hline 1 & 0.1 & 0.5 & 5 & 128.83 & 4.87 \\
2 & 0.1 & 1.5 & 15 & 157.76 & 5.96 \\
3 & 0.1 & 3 & 45 & 120.10 & 4.54 \\
4 & 0.5 & 0.5 & 5 & 146.08 & 5.52 \\
5 & 0.5 & 1.5 & 15 & 147.13 & 5.56 \\
6 & 0.5 & 3 & 45 & 111.30 & 4.21 \\
7 & 1 & 0.5 & 5 & 101.17 & 3.82 \\
8 & 1 & 1.5 & 15 & 120.97 & 4.57 \\
9 & 1 & 3 & 45 & 93.62 & 3.54 \\
$\mathrm{TiO}_{2}$ & - & - & - & 26.46 & - \\
\hline
\end{tabular}

whereas the degradation efficiency for $\mathrm{I}^{-\mathrm{TiO}_{2}}$ reached $86 \%$. The increase in efficiency of the degradation process was observed due to the doping of titania nanotubes with iodine which caused a shift in the absorbance ability towards visible light. Such an improvement can also be explained in terms of a more effective separation of photogenerated charges: electron and holes.

In Fig. 7b,c, the changes of PL intensity versus irradiation time are plotted. As it can be seen, the generated spectra have a very similar shape with maximum located at $535 \mathrm{~nm}$. Within the duration of exposure to UV-Vis illumination of TA solution, the fluorescence intensity increases gradually. However, in the case of iodine-doped $\mathrm{TiO}_{2}$, the rate of the fluorescence change is much higher when compared to cases when pristine titania is used as the catalyst. This difference results from changes in the formation rate of $\cdot \mathrm{OH}$ radicals and implies that the doped nanotubes are characterized by a much higher photocatalytic activity than the pure sample. Therefore, the presence of iodine dopant could effectively induce the intense absorbance of visible light, thereby generating a higher $\bullet \mathrm{OH}$ radical concentration. Additionally, the iodine dopant could facilitate the separation and transfer of photoinduced electrons and holes pairs, leading to a longer lifetime of generated charge carriers $[15,16]$.

\section{Conclusions}

There was proposed optimization procedure in order to achieve highly photoactive and stable titania nanotube arrays doped with iodine. It has been found that electrolyte concentration, reaction voltage, and time are the most crucial factors affecting the photoelectrochemical response of the doped material. According to the inspection performed via scanning electron microscopy, the electrochemical treatment in electrolyte containing $\mathrm{KI}$ as iodine precursor does not affect the tubular architecture of the as-anodized titania. The presence of iodine species was confirmed by both the energy-dispersive $\mathrm{X}$-ray spectroscopy and X-ray photoelectron spectroscopy techniques. An iodine-doped sample possesses lower bandgap energy than pure titania but the material is still characterized by an anatase crystalline phase. The test performed under sample irradiation showed that iodine doping radically improves the photocatalytic activity as well as the generation of a photocurrent. On the basis of the highest photocurrent enhancement, the optimal conditions were determined as follows: $1.5 \mathrm{~V}$ of reaction voltage, duration time of $15 \mathrm{~min}$, and concentration of $0.1 \mathrm{M} \mathrm{KI}$. After $2 \mathrm{~h}$ of constant illumination, the degradation of methylene blue reached $40 \%$ in the presence of pure titania nanotubes, whereas in the case of $\mathrm{I}^{-} \mathrm{TiO}_{2}$, a

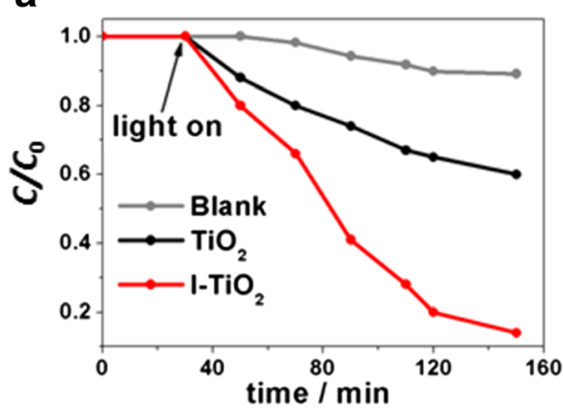

b

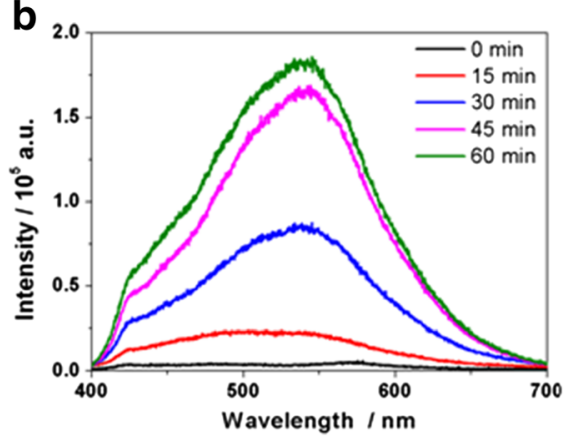

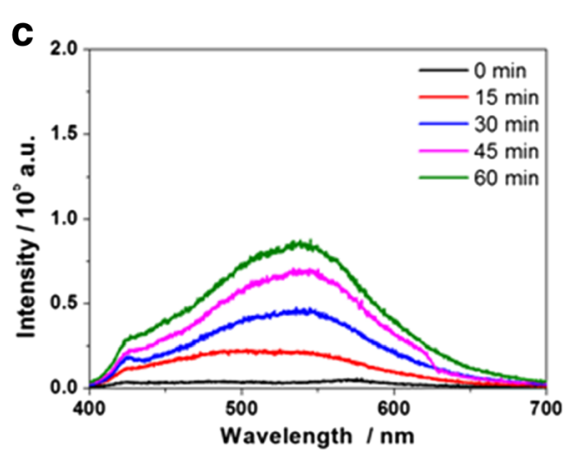

Fig. 7 a Photocatalytic performance of the obtained samples under UVVis illumination and photoluminescence spectra changes with Xenon lamp irradiation time on $\mathrm{I}_{-} \mathrm{TiO}_{2}(\mathbf{b})$ and pure $\mathrm{TiO}_{2}$ (c) nanotubes in
$50 \mathrm{mM}$ TA (in $2 \mathrm{mM} \mathrm{NaOH}$ ). The doping conditions are as follows: reaction voltage of $1.5 \mathrm{~V}$, reaction time of $15 \mathrm{~min}$, and electrolyte concentration of $0.1 \mathrm{M}$ 
this value reached $86 \%$. In summary, because of the remarkably improved photoactivity of $\mathrm{I}_{-} \mathrm{TiO}_{2}$ in comparison to pristine $\mathrm{TiO}_{2}$, the iodine doping approach shows good potential for titania modification resulting in a material that could be applied as a photoelectrode in dye-sensitized solar cells or for sustainability in the photocatalytic degradation of hazardous chemicals.

Acknowledgments This work was supported financially by the Polish National Science Center: Grant No 2012/07/D/ST5/02269.

Open Access This article is distributed under the terms of the Creative Commons Attribution 4.0 International License (http:// creativecommons.org/licenses/by/4.0/), which permits unrestricted use, distribution, and reproduction in any medium, provided you give appropriate credit to the original author(s) and the source, provide a link to the Creative Commons license, and indicate if changes were made.

\section{References}

1. Shiraishi F, Ishimatsu T (2009) Chem Eng Sci 64:2466-2472

2. Mor GK, Paulose M, Shankar K, Varghese OK, Ggrimes CA (2005) Nano Lett 5:191-195

3. Yang Y, Lee K, Kado Y, Schmuki P (2012) Electrochem Commun 17:56-59

4. He H, Liu C, Dubois KD, Jin T, Louis ME, Li G (2012) In Eng Chem Res 51:11841-11849

5. Roy P, Berger S, Schmuki P (2011) Angew Chemie Int 50:2904 2939

6. Zwilling V, Aucouturier M, Darque-Ceretti E (1999) Electrochim Acta 44:921-929

7. Matsuda A, Sreekantan S, Krengvirat W (2013) J Asian Ceram Soc 1:203-219

8. Siuzdak K, Szkoda M, Sawczak M, Lisowska-Oleksiak A (2015) New J Chem 39:2741-2751
9. Tang X, Li D (2008) J Phys Chem C 112:5405-5409

10. Zang Y, Fu W, Yang H, Liu S, Sun P, Yuan M, Ma D, Zhao W, Sui Y, Li M, Li Y (2009) Thin Solid Films 518:99-105

11. Bessegato GG, Cardoso JC, Zanoni MVB (2015) Catal Today 240: 100-106

12. Szkoda M, Siuzdak K, Lisowska-Oleksiak A, Karczewski J, Ryl J (2015) Electrochem Commun 60:212-215

13. Su Y, Xiao Y, Fu X, Deng Y, Zhang F (2009) Mater Res Bull 44: 2169-2173

14. Sulka GD, Kapusta-Kolodziej J, Brzozka A, Jaskula M (2013) Electrochim Acta 104:526-535

15. Che M, Védrine JC (2012) Characterization of solid materials and heterogeneous catalysts: from structure to surface reactivity. John Wiley and Sons, New York City

16. Zhou M, Zhang J, Cheng B, Yu H (2012) Int J Photoenergy 2012: $1-7$

17. Cheng X, Liu H, Chen Q, Li J, Wang P (2013) Electrochim Acta 103:134-142

18. Siuzdak K, Szkoda M, Lisowska-Oleksiak A, Grochowska K, Karczewski J, Ryl J (2015) Appl Surf Sci 357:942-950

19. Lisowska-Oleksiak A, Szybkowska K, Jasulaitiene V (2010) Electrochim Acta 55:5881-5885

20. Bagwasi S, Tian B, Chen F, Zhang J (2012) Appl Surf Sci 258: 3927-3935

21. Choudhury B, Dey M, Choudhury A (2013) Inter Nano Lett 3:25-33

22. Yu JG, Dai GP, Cheng B (2010) J Phys Chem C 114:19378-19385

23. Li W, Liang R, Hu A, Huang Z, Norman Y (2014) RSC Adv 4: 36959-36966

24. Shi N, Lite X, Fan T, Zhou H, Ding J, Zhang F (2011) Energy Environ Sci 4:172-180

25. Wang J, Li B, Ni T, Dai T, Lu Y (2015) Composites Sci Technol 109:12-17

26. Zhang X, Zhang L (2010) J Phys Chem C 114:18198-18206

27. Cabibil H, Ihm H, White JM (2000) Surf Sci 447:91-104

28. Wang Y, Ren J, Liu G, Peng P (2011) Mater Chem Phys 130:493-499

29. Wang J, Bai H, Tan X, Lian J (2006) Appl Surf Sci 253:1988-1994 